\title{
Connected Facility Quality and Customers' Consummation: A learning Study Report of the Selected Commercial Banks in Riyadh (Saudi Arabia)
}

\author{
Mohammad Al Motairi ${ }^{1}$, Soad Al Meshal ${ }^{1}$, Aftab Alam ${ }^{2}$ \\ ${ }^{1}$ Department of Marketing College of Business Administration \\ King Saud University Riyadh Saudi Arabia \\ ${ }^{2}$ Uni KI Business School (University of Kuala Lumpur Malaysia)
}

\begin{abstract}
Online banking is one of the main functions of modern banking in existing banking operations across the globe. Online banking operations improve the performance of the banking industry and helps customers to reduce their transaction costs. This study aims to investigate the relationship between online banking services offered by $\mathrm{Al}$ Rajhi Bank, National Commercial bank and Riyadh Bank. Various dimensions such as movable, tangible assets, reliability, responsiveness and empathy as determinants of customer satisfaction have been used. These dimensions are based on the SERVQUAL model developed by Han and BEC (2004). The reliability and validity of the dimensions were examined by the alpha value of the Cronbach test. The value of this test is 0.74 , representing a good internal scale consistency. Descriptive statistics and dichotomous logistic regression model have been used to study the relationship various dimensions and customer satisfaction. The sample size is consisting of 100 customers. Purposive sampling technique was used to select customers who familiar with online banking. Thus various university students were selected from the Kingdom of Saudi Arabia in Riyadh. The names of these universities are: King Saud University, University of Islamic Imam Muhammad Bin Saud and Prince Sultan University. The study shows that the selected dimensions; tangible, reliability, responsiveness and empathy are important determinants of overall satisfaction of the customer, but with different levels. Moreover, the study shows that tangible property and reliability to improve most influential dimensions of the overall probability of the customers' satisfaction with the rest of the dimensions proposed in this study.
\end{abstract}

KEYWORD: Online banking, Customer satisfaction, Islamic banks

JEL classification codes: M39, О32

\section{Council for Innovative Research}

Peer Review Research Publishing System

Journal: International Journal of Management \& Information Technology

Vol. 9, No. 2

editor@cirworld.com

www.cirworld.com, member.cirworld.com 


\section{INTRODUCTION}

Web-oriented services have brought novel changes in all sectors of a modern economy particularly, in the banking sector. Perhaps the banking industry is more competitive, innovative and customer oriented than any other industry in the services sector. Online banking services are an interesting alternative to the information store service to visit or telephone call centers to increase the number of clients (Kenova P, 2006). E technical service facilitates both; Stakeholders and customers in different ways and channels. Internet Banking banks help create and maintain close relations with its customers reduce operating costs and corrected and is a more efficient and improved financial performance (Rod M, 2008). On the other hand, the customers also benefit from this technology having easy access to financial services and reduction in transaction cost (Yang, 2004). The provision of online quality services to the banking customers plays a vital role to maintain or enhance customer satisfaction. The facility of internet banking to the customers is considered as a competitive necessity. The banks assure quality online services to their customers in order to enable them to enjoy the latest wide range of financial facilities with minimum transaction cost (Rod M A. N., 2008). The success or failure of any business entity including the banking sector depends on their corresponding customers' satisfaction. Increasing customer satisfaction will yield material benefits such as higher market shares, more profit and non-material benefits such as good reputation, confidence of the customers, good will etc.

The study aims to investigate the relationship between online banking services provided by different banks in Riyadh (Saudi Arabia) namely; Al- Rajhi bank, National commercial bank and Riyadh bank- Riyadh to gauge how efficiently these banks provide online banking facilities to their corresponding clients? Different dimensions such as; tangibles, reliability, responsiveness, and empathy have been taken as determinants of customer satisfaction. These dimensions are created on the SERVQUAL model proposed by (Han Sang, 2004).

There is no principal difference between conventional and internet banking except accessing and making transactions of financial matters through your computer rather than paper completed transactions. Internet banking facilitates you in performing multiple financial tasks such as checking your balance, payment of utility bills, money transfers, online purchasing and investment etc. This ease has attracted many customers and has enhanced customer satisfaction across the world.

\section{Material and Methods}

In order to investigate the Study the relationship between service and customer satisfaction online, the theoretical framework developed under the model, the SERVQUAL and modified, developed by (Zeithaml 1990). We have refined the modified version of the SERVQUAL model, by (Han blood, 2004). This model proposes four important aspects in terms of the quality of the service. These are namely; Moving body, reliability, responsiveness and empathy. The following table contains a detailed description of these dimensions.

Table 1: Modified dimensions of SERVQUAL model and their description

\section{SERVQUAL Dimensions Description of dimension}

Tangibles

Online banking is with modern facilities. Ease and availability of information on the Bank's website.

Dependability Includes the technical operation of the website and the accuracy of the promises of service (delivery as promised) and product information

Receptiveness Quick response and the ability to help, if there a problem or a question

Understanding Provision of care and discrete care to customers providing by call centers or Web superintendents.

Basis: (Han Sang, 2004)

\subsection{Nature of Data and its Description}

The study uses a purposive sampling technique because the data is collected from all those clients who are familiar with the online banking system. Therefore, this study takes into consideration only online banking 
customers while the rest of the customers are lying outside the scope of the study.

The selected customers are the students of the selected universities of the Kingdom of Saudi Arabia located in Riyadh. These universities are namely: King Saud University, Imam Muhammad Bin Saud Islamic University and Prince Sultan University. The data collected from the students through a detailed survey established by (Han Sang, 2004) to investigate connected online digital banking services and client's satisfaction".

The survey covers four dimensions of connected online digital banking services; Tangibles, Reliability, Responsiveness and Empathy. Four to five questions, related to each dimension, were asked from the respondents. The measurement scale of the questions was ordinal scale and thus the responses of the respondents were ordered from 1-5 (1=strongly disagree, 5=strongly agree).

\subsection{Analytical Techniques}

A set of analytical techniques has been used to investigate the relationship between online banking services available to customers and customers' satisfaction in Saudi Arabia.

Firstly, The Reliability and validity of the dimensions examined by the Cronbach alpha test, Internal reliability can be tested with alpha (Cornbach). It measures the degree to which to respond for collected one, correlate the element strong with each other (Kenova P, 2006; Sidat, 2008)

Cronbach's $\alpha$ is describing as;

$$
\alpha=\frac{K}{K-1}\left(1-\frac{\sum_{i=1}^{K} \sigma_{Y_{i}}^{2}}{\sigma_{X}^{2}}\right)
$$

Everywhere, $\mathrm{K}$ is the number of components (K items or Test lets) $\sigma_{X}^{2}$ is the variance of the observed total test results and $\sigma_{Y_{i}}^{2}$ the variance of component $i$ in the latest example of People/Persons

Secondly, as with the ordinal data collected, are median and mode the best measures of central tendency of the data.

Thirdly, we have used the binary logistic model than the one of showing the overall probability satisfaction variations assumed that a modification in the designated dimensions occurs. The overall satisfaction has been peroxide by median score. If a respondent scores four or more in at least two dimensions then this situation is considered as overall satisfaction and vice versa.

Logistic perfect model stated as:

$\mathrm{Yi}=\left[\frac{\alpha \mathrm{i}}{(1-\alpha \mathrm{i})}\right]=\beta 0+\beta 1 \mathrm{Y} 1+\beta 2 \mathrm{Y} 2+\beta 3 \mathrm{Y} 3+\beta 4 \mathrm{Y} 4+\beta 5 \mathrm{Y} 5+\mu \mathrm{i}$

Where;

$\mathbf{Y i}=\left[\frac{\boldsymbol{\alpha i}}{(\mathbf{1}-\boldsymbol{\alpha i})}\right]$ are odd relations for an increase in the overall satisfaction of each participant to the probability that a single overall satisfaction has not increased.

$\mathrm{Y} 1$ = Age of the customers

$\mathrm{Y}_{2}=$ Median tangible score of customers.

$\mathrm{Y}_{3}=$ Median reliability score of customers.

$\mathrm{Y}_{4}=$ Median responsive score of customers.

$\mathrm{Y}_{5}=$ Median empathy score of customers.

\section{ANALYSIS AND DISCUSSION}

The Cronbach's $\alpha$ result is reported here to show the reliability of different dimensions we proposed for investigating the relationship between online banking services and customer satisfaction.

Table-1: Reliability Statistics

\footnotetext{
${ }^{1}$ For detail of questionnaire please see appendix-I
} 


\begin{tabular}{|l|l|l|}
\hline Cronbach's Method Alpha & $\begin{array}{l}\text { Cronbach's Methods Alpha } \\
\text { Founded on Consistent Matter }\end{array}$ & No. of Matters \\
\hline 0.741 & 0.743 & 18 \\
\hline
\end{tabular}

Source: Author's own calculation (SPSS 19 version estimation)

Chronbach's Alpha value is 0.741 which represents a good level of internal consistency of the scale for all eighteen numbers of questions. Preferably, the Cronbach's Method Alpha constant of a gage must be 0.70 and overhead (Pallent, 2009).

Table-2: Item-Total Statistics ${ }^{2}$

\begin{tabular}{|c|c|c|c|c|c|c|}
\hline Dimension & Questions & $\begin{array}{l}\text { Gage } \\
\text { Mean if } \\
\text { Matter } \\
\text { Erased }\end{array}$ & $\begin{array}{l}\text { Gage } \\
\text { Modification if } \\
\text { Matter Erased }\end{array}$ & $\begin{array}{l}\text { Modified } \\
\text { Matters-Total } \\
\text { Association }\end{array}$ & $\begin{array}{l}\text { Squared } \\
\text { Multiple } \\
\text { Association }\end{array}$ & $\begin{array}{l}\text { Cronbach's } \\
\text { Methods Alpha } \\
\text { if } \text { Matters } \\
\text { Erased }\end{array}$ \\
\hline \multirow{5}{*}{ Tangibility } & Q1 & 67.7250 & 41.589 & .314 & .503 & .730 \\
\hline & Q2 & 67.5000 & 42.205 & .409 & .620 & .725 \\
\hline & Q3 & 67.8500 & 42.592 & .254 & .420 & .734 \\
\hline & Q4 & 67.8500 & 41.464 & .350 & .529 & .727 \\
\hline & Q5 & 68.0000 & 40.615 & .375 & .498 & .724 \\
\hline \multirow{5}{*}{ Dependability } & Q6 & 67.9500 & 41.741 & .297 & .657 & .731 \\
\hline & Q7 & 67.6750 & 42.225 & .288 & .519 & .732 \\
\hline & Q8 & 67.7250 & 41.999 & .307 & .424 & .730 \\
\hline & Q9 & 67.7250 & 41.897 & .259 & .636 & .735 \\
\hline & Q10 & 67.7500 & 42.551 & .230 & .597 & .737 \\
\hline \multirow{4}{*}{ Receptiveness } & Q11 & 67.6500 & 40.131 & .413 & .559 & .721 \\
\hline & Q12 & 67.7250 & 41.333 & .322 & .390 & .729 \\
\hline & Q13 & 67.7500 & 40.910 & .338 & .699 & .728 \\
\hline & Q14 & 67.9500 & 40.459 & .317 & .476 & .730 \\
\hline \multirow{4}{*}{ Understanding } & Q15 & 68.0000 & 42.410 & .240 & .326 & .736 \\
\hline & Q16 & 67.7000 & 42.010 & .336 & .410 & .728 \\
\hline & Q17 & 68.2250 & 38.846 & .404 & .378 & .721 \\
\hline & Q18 & 67.8500 & 41.669 & .284 & .481 & .732 \\
\hline
\end{tabular}

Source: Author's own calculation (SPSS 19 version estimation)

The table below presents statistics on the relationships between individual elements and the extent of the whole. Colum 3 and 5 are the most important calculations for the building of a relationship between the variables. Corrected item-total correlations are to scale correlations between the individual elements and complete results. If the scale is consistent, you expect these correlations to be quite strong. The last column represents what Cronbach's methods alpha if we deleted something and recalculated on the basis of the remaining elements. We

${ }^{2}$ Questions related to different dimesions have been assigned differet colors. 
can observe that the removal of all questions would result in a lower Cronbach Method. Therefore, we want to delete not a question. Cronbach's Methods alpha offers just for a set of variables, for example issues a coefficient of reliability.

Next, we calculate descriptive statistics of the proposed dimensions to investigate the average behavior of the respondents regarding their overall satisfaction towards the online banking facilities in Riyadh (Saudi Arabia). The data collected on the ordinal so median and mode is the best measures of central tendency, the area and Inter Quartile Range (IQR) are the best measures of dispersion.

Taking median and mode for each dimension to reveal the respondents' satisfaction about the online banking facility in Riyadh (Saudi Arabia), Table-3 reveals that overall median for each dimension is 4 . This reveals that respondents are satisfied with the online banking facilities provided by the commercial banks in Riyadh. These results provide an insight into the updated facilities, use of modern technology, the efficiency of the banking industry in Riyadh in particular and Saudi Arabia in general. Table-3 shows descriptive statistics of respondents' responses.

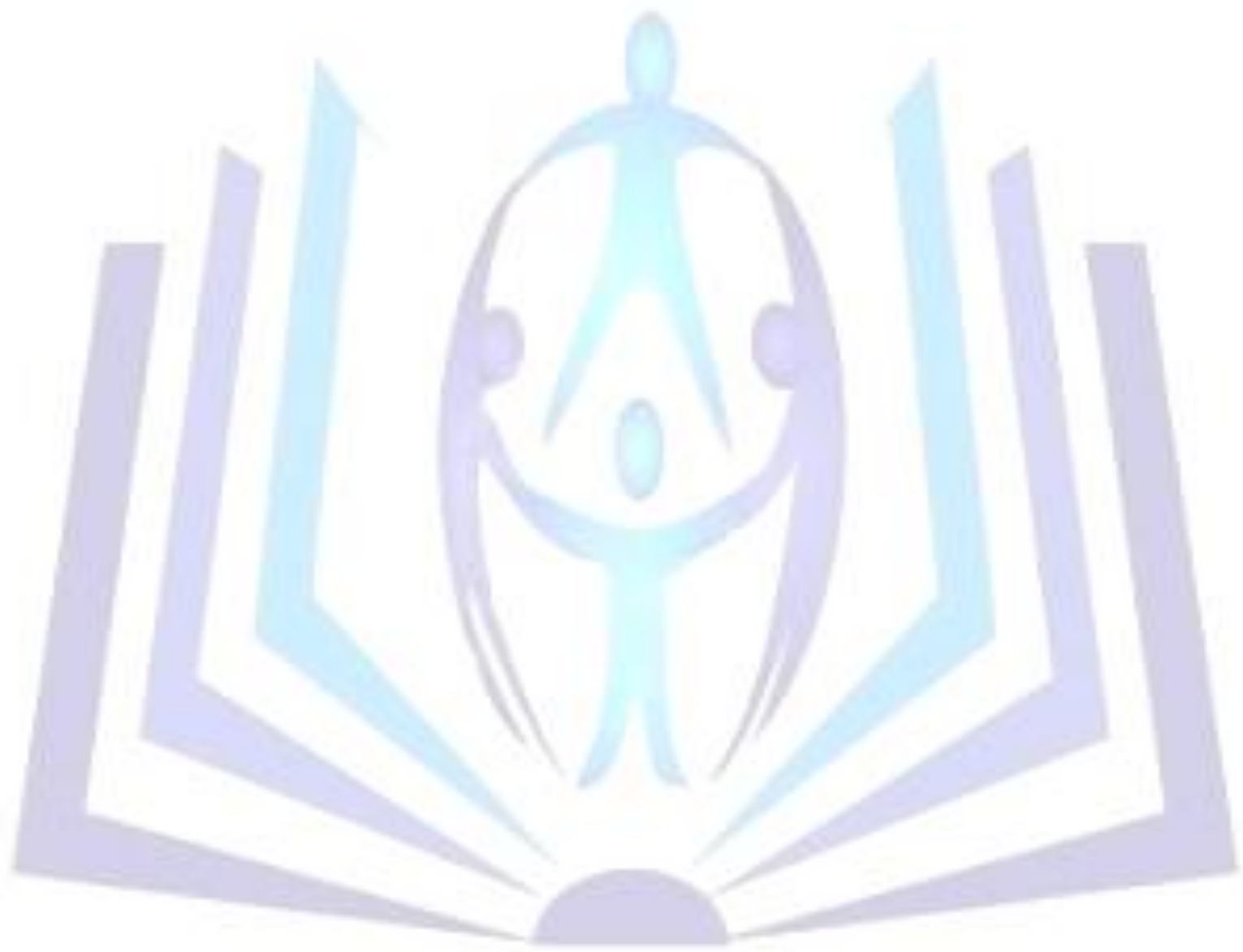


Table-3 Descriptive statistics of respondents' responses ${ }^{3}$

\begin{tabular}{|c|c|c|c|c|c|c|c|c|c|c|c|c|c|c|c|c|c|c|}
\hline & \multicolumn{5}{|c|}{ Tangibility } & \multicolumn{5}{|c|}{ Dependability } & \multicolumn{4}{|c|}{ Receptiveness } & \multicolumn{4}{|c|}{ Understanding } \\
\hline & Q1 & Q2 & Q3 & Q4 & Q5 & Q6 & Q7 & Q8 & Q9 & Q10 & Q11 & Q12 & Q13 & Q14 & Q15 & Q16 & Q17 & Q18 \\
\hline Mean & 4.0 & 4.4 & 4.0 & 3.9 & 4.0 & 3.9 & 4.1 & 4.1 & 4.1 & 3.9 & 4.1 & 4.0 & 4.0 & 4.5 & 3.9 & 4.0 & 3.8 & 4.6 \\
\hline $\begin{array}{l}\text { Standard } \\
\text { Error }\end{array}$ & 0.1 & 0.1 & 0.1 & 0.1 & 0.1 & 0.1 & 0.1 & 0.1 & 0.1 & 0.1 & 0.1 & 0.1 & 0.1 & 0.1 & 0.1 & 0.0 & 0.1 & 0.1 \\
\hline Median & 4.0 & 4.0 & 4.0 & 4.0 & 4.0 & 4.0 & 4.0 & 4.0 & 4.0 & 4.0 & 4.0 & 4.0 & 4.0 & 5.0 & 4.0 & 4.0 & 4.0 & 5.0 \\
\hline Mode & 4.0 & 4.0 & 5.0 & 3.0 & 5.0 & 3.0 & 4.0 & 4.0 & 5.0 & 3.0 & 5.0 & 5.0 & 4.0 & 5.0 & 4.0 & 4.0 & 4.0 & 5.0 \\
\hline $\begin{array}{l}\text { Standard } \\
\text { Deviation }\end{array}$ & 0.8 & 0.6 & 0.8 & 0.8 & 0.9 & 0.8 & 0.8 & 0.8 & 0.9 & 0.9 & 0.8 & 0.8 & 0.6 & 0.9 & 0.6 & 0.5 & 0.8 & 0.8 \\
\hline $\begin{array}{l}\text { Sample } \\
\text { Variance }\end{array}$ & 0.7 & 0.3 & 0.7 & 0.7 & 0.8 & 0.7 & 0.6 & 0.6 & 0.8 & 0.7 & 0.7 & 0.7 & 0.4 & 0.8 & 0.3 & 0.2 & 0.6 & 0.6 \\
\hline Kurtosis & -1.3 & 1.6 & -1.5 & -1.5 & -1.3 & -1.4 & -1.4 & -0.8 & -1.2 & -1.4 & -1.0 & -1.6 & 1.0 & 1.8 & 1.4 & 1.6 & 1.6 & 0.9 \\
\hline Skewness & 0.0 & -0.6 & -0.1 & 0.2 & -0.2 & 0.0 & -0.1 & -0.3 & -0.3 & 0.1 & -0.4 & 0.0 & -0.3 & -1.7 & -0.4 & 0.1 & -1.2 & -1.5 \\
\hline Range & 3.0 & 3.0 & 2.0 & 2.0 & 3.0 & 3.0 & 2.0 & 3.0 & 3.0 & 3.0 & 3.0 & 2.0 & 3.0 & 3.0 & 3.0 & 2.0 & 3.0 & 3.0 \\
\hline Minimum & 2.0 & 2.0 & 3.0 & 3.0 & 2.0 & 2.0 & 3.0 & 2.0 & 2.0 & 2.0 & 2.0 & 3.0 & 2.0 & 2.0 & 2.0 & 3.0 & 2.0 & 2.0 \\
\hline Maximum & 5.0 & 5.0 & 5.0 & 5.0 & 5.0 & 5.0 & 5.0 & 5.0 & 5.0 & 5.0 & 5.0 & 5.0 & 5.0 & 5.0 & 5.0 & 5.0 & 5.0 & 5.0 \\
\hline Sum & 392 & 437.0 & 400.0 & 387.0 & 397.0 & 391.0 & 403.0 & 406.0 & 401.0 & 388.0 & 405.0 & 396.0 & 399.0 & 448.0 & 389.0 & 400.0 & 380.0 & 452.0 \\
\hline Count & 99.0 & 99.0 & 99.0 & 99.0 & 99.0 & 99.0 & 99.0 & 99.0 & 99.0 & 99.0 & 99.0 & 99.0 & 99.0 & 99.0 & 99.0 & 99.0 & 99.0 & 99.0 \\
\hline
\end{tabular}

\footnotetext{
${ }^{3}$ Questions related to different dimesions have been assigned differet colors.
} 
L Pogistic regressions estimates are reported along with other statistics are reported in table- 4 .

Table-4: Logistic Regression Estimates

\begin{tabular}{|l|l|l|l|l|l|l|}
\hline & Bi & S.E & Wald-test & df & Sig. & Exp(B) \\
\hline Age & -0.71 & .164 & .186 & 1 & .666 & 0.4932 \\
Tangibles & 2.467 & .986 & 6.257 & 1 & .012 & 11.782 \\
Dependability & 2.332 & .840 & 7.699 & 1 & .006 & 10.297 \\
Receptiveness & 1.251 & .781 & 2.567 & 1 & .109 & 3.495 \\
Understanding & .975 & .584 & 2.791 & 1 & .095 & 2.652 \\
Constant & -22.917 & 8.360 & 7.515 & 1 & .006 & .000 \\
\hline
\end{tabular}

Source: Author's own calculation (SPSS 19 version estimation)

$$
\mathbf{Y i}=\left[\frac{\alpha \mathrm{i}}{(1-\alpha \mathrm{i})}\right]=-22.917-0.71 \mathrm{X} 1+2.47 \mathrm{X} 2+2.33 \mathrm{X} 3+1.25 \mathrm{X} 4+0.975 \mathrm{X} 5
$$

The binary logistic regression estimates reveal an overall positive relationship between online facilities provided by the banking industry in Saudi Arabia and customers' satisfaction. All slope coefficients are positive except age of the customers. In order to interpret the logistic estimates, it is oftenly preferred by the econometrisions to take a anti-log of the estimates for meaningful interpretation of the results. The effect of age on overall satisfaction of customers is negligible (0.4932). Tangibles dimensions are the most important determinants of customer overall satisfaction. If the median tangible dimensions increase by one unit then the probability of customers' overall satisfaction increases by 11.78 times. Similarly, reliability dimensions are the $2^{\text {nd }}$ important determinants of customers' overall satisfaction. If the median reliability dimensions increase by one unit then the probability of overall customer satisfaction increases by 10.29 times. In the similar way, median reliability and responsiveness increases by one unit the probability in favor of overall satisfaction increase by 3.45 and 2.652 respectively. All dimensions are statistically significant at 99 percent confidence level except reliability and responsiveness.

\section{CONCLUSION AND FINDINGS}

The study aims to investigate the relationship between online banking services provided by different banks in Riyadh (Saudi Arabia) namely; Al- Rajhi bank, National commercial bank and Riyadh bank- Riyadh. The study uses three empirical investigation techniques e-g, Chronbach's Alpha statistics for internal scale of consistency of various dimensions proposed, Descriptive statistics especially, median and mode to reveal the average satisfaction of the customers and finally, the binary logistic regression model to predict changes in overall level of satisfaction given that a median change in any dimension. The results of the study favor the previous important studies such as; (Yang, 2004; Yang Z. J., 2004; Mobarek, 2007; Nupur, 2010).

The study reveals the following important findings:

1. The Chronbach's Methods of Alpha statistics for internal scale of consistency was used. The value of this test is reported as 0.741 which represents a good scale of internal consistency and relevancy of all questions related to the overall level of satisfaction.

2. The overall median score, for all customers, is 4 which represent an overall level of satisfaction of customers regarding the various online facilities provided by the selected banks in Riyadh.

3. The empirical results of logistic regression reveal that age of the customers does not significantly influence their corresponding overall level of satisfaction. The results further reveal that all the selected dimensions; tangibles, reliability, responsiveness and empathy are the significant determinants of overall satisfaction of the customer but with diverse significance levels.

4. The study further reveals that tangibles and reliability are most influential dimensions to enhance customers' overall probability of satisfaction as compared to the rest of dimensions proposed in this study.

\section{RECOMMENDATIONS AND POLICY IMPLICATIONS}

Based on the findings of the study, the study summarizes the recommendation of the study as;

1. Diverse online banking facilities are the important determinants of overall customers' satisfaction therefore customers' oriented banks should make note this phenomenon to increase their customers' circle by providing more reliable, innovative online facilities to their customers. 
2. Dimensions such as tangibles and reliability among others are the most important determinants of customers' overall level of satisfaction. This phenomenon can be used by the banking industry in Riyadh to accelerate the growth of their customer satisfaction by focusing on all other dimensions with a particular focus on tangibles and reliability dimensions of customer satisfaction.

\section{LIMITATION OF THIS RESEARCH}

The conclusions and recommendations of this study are based on the perception of respondents. The information about the online service excellence and customer satisfaction, regarding the commercial banks in Riyadh is collected from 100 students. The sample is significantly low and thus the value outcome can't be widespread for the entire commercial banks operating across the Saudi Arabia.

\section{BIBLIOGRAPHY}

[1] Han Sang, B. S. (2004). Antecedents and Consequences of Service Quality in Online Banking: An Application of the SERVQUAL Instrument. Advance in Consumer Research, 31, 208-214.

[2] Kenova P, V. J. (2006). Quality Online Banking Service. Jonkoping university.

[3] Mobarek, A. (2007). E-BANKING PRACTICES AND CUSTOMER SATISFACTION- A CASE STUDY IN BOTSWANA. Dept. of Accounting and Finance, University of Botswana.

[4] Nupur, J. M. (2010). E-Banking and Customers' Satisfaction in Bangladesh:An Analysis. International Review of Business Research Papers., 6, 145-156.

[5] Pallent, J. (2007). SPSS Survival Manual: A Step by Step Guide to Data Analysis using SPSS for Windows. McGraw England.

[6] Rod M, A. N. (2008). An examination of the relationship between service quality dimensions, overall internet banking service quality and customer satisfaction: A New Zealand study. Marketing Intelligence \& Planning, 27(1).

[7] Rod M, A. N. (2008). An examination of the relationship between service quality dimensions, overall internet banking service quality and customer satisfaction: A New Zealand study. Marketing Intelligence \& Planning, 27(1).

[8] Sidat, S. (2008). Measuring Service Quality using SEWRVQUAL Model: A Case Study of E-Retiling in Iran. University Technology Malaysia.

[9] Yang, F. (2004). Online service quality dimensions and their relationships with satisfaction: A content analysis of customer reviews of securities brokerage services. International Journal of Service Industry Management, 15(3), 302-326.

[10] Yang, Z. J. (2004). Measuring customer perceived online service quality Scale development and managerial implications. International Journal of Operations \& Production Management, 24(11), 1149-1174.

[11] Zeithaml, P. .. (1990). Delivering Quality Service; Balancing Customer Perceptions and Expectations. Free Press.

\section{Appendix-1: Questionnaire}

Sizes Questions

Tangibles

Q-1: "ABC” Online banking has modern equipment \&latest

Banking technology.

Q-2: The website of the "ABC" online bank is visually attractive.

Q-3:The website of the "ABC" online bank easily accessible

Q-4: The website of the "ABC" online bank provides you with

Relevant information.

Q5) The website of the "ABC" online bank is easy to use and

Circumnavigate.

Q-1: When "ABC" online bank potentials to do somewhat by a

Sure time, it does so. 
Q-2: Services or call centers of "ABC" online banks have operating Hours convenient for all its customers.

Q-3: Services, call centers, and web administrators of "ABC" online Bank gives your personal attention.

Q-4 Services, call centers, and web administrators of "ABC" online Banks have your best interests at heart.

Q-5: Services, call centers, and web administrators of "ABC" online bank comprehend your exact desire 